\title{
Particularities of Using Contrast Agents in Diagnosis of Stroke
}

\author{
DAN IULIAN CUCIUREANU1, CRISTIAN STATESCU2*, RADU ANDY SASCAU2*, TUDOR CUCIUREANU3*, \\ VICTOR ALEXANDRU CONSTANTINESCU ${ }^{1}$, DELIA HINGANU ${ }^{4}$, CRISTINA PREDA5 ${ }^{5}$, MARIUS VALERIU HINGANU, \\ MIH AELA DANA TURLIUC 6
}

${ }^{1}$ Grigore T. Popa University of Medicine and Pharmacy, Faculty of Medicine, III-rd Medical Department, 16 Universitatii Str., 700115, Iasi, Romania

${ }^{2}$ Grigore T. Popa University of Medicine and Pharmacy, Faculty of Medicine, 16 Universitatii Str., 700115, lasi, Romania

${ }^{3}$ Grigore T. Popa University of Medicine and Pharmacy, Faculty of Medicine, I-st Medical Department, 16 Universitatii Str., 700115, Iasi, Romania

${ }^{4}$ Grigore T. Popa University of Medicine and Pharmacy, Faculty of Medicine, Department of Morpho-Functional Sciences I, 16 Universitatii Str., 700115, lasi, Romania

${ }^{5}$ Grigore T. Popa University of Medicine and Pharmacy, Faculty of Medicine, II-nd Medical Department, 16 Universitatii Str., 700115, Iasi, Romania

${ }^{6}$ Grigore T. Popa University of Medicine and Pharmacy, Faculty of Medicine, II-nd Surgical Department, 16 Universitatii Str., 700115, Iasi, Romania

\begin{abstract}
Stroke is the first cause of disability, the second cause of dementia and the third cause of mortality in industrialized countries. Due to its increasing incidence, there is a need to study the possibilities of early prevention and diagnosis. Our study was conducted on a group of 165 selected patients diagnosed with different forms of ischemic strokes, aged between 25 and 50 years. We explored them using contrast injected MRI technique, to show the usefulness of this radiologic method and to propose a protocol for the investigation of clinically diagnosed patients with stroke. Contrast injected MRI is demonstrated to be a gold technique in exploring early cases of ischemic stroke with different anomalies. Special agents combined with this technique allows assessment of the functionality of the blood-brain barrier, revealing the real ischemic penumbra.
\end{abstract}

Keywords: ischemic stroke, blood-brain barrier, MRI with contrast agents

Stroke is still a public health problem, with a high incidence in the working age population. Approximately one-third of ischemic strokes in young people remain undetermined, making secondary prevention unsuitable. The consumption of toxic substances and occult cardiac arrhythmia could be the cause of these ischemic strokes.

An ischemic stroke is a prolonged interruption or insufficiency of the arterial supply in a cerebral zone, clinically translated by focal neurological signs. This signs are respecting the territory of the concerned artery, with sudden installation or by successive strokes, the most common of which is hemiplegia.

Ischemic stroke (IS) is one of the forms of cerebrovascular disease $[1,2]$. Unfortunately, the possibilities of treatment in IS are not commensurate with the advances made in its pathophysiological knowledge.

There are two types of ischemic strokes: transient (TIS) whose signs are fully remitted within 1 hours and constituted which lead to a permanent deficit, reflecting the constitution of a cerebral infarction [3, 4].

A haemorrhagic stroke could also has consequences of a similar severity to ischemic strokes. Each type of stroke has a specific treatment that requires an early differential diagnosis.

Classification of cerebrovascular diseases are made in relation with its topography, onset, pathophysiological mechanism or is considering the timing cryteria.

Another classification divides strokes into: asymptomatic - includes patients with no symptoms of cerebral or retinal vascular disease, but paraclinical investigations (CT, MRI) reveal signs of cerebrovascular disease; focal cerebral dysfunction which can be:

- transient ischemic attack in the carotid or vertebrobasilar system.
- constituted (cerebral infarction) by one of the mechanisms: thrombotic - is achieved by overlapping the thrombus on the atheroma plate; embolic-distal embolization and occlusion of an artery $[5,6]$.

Hemodinamic exploration mechanism are compulsory in patients with severe stenosis or proximal arterial occlusions with inadequate collateral circulation, with a critical decrease in global cerebral infusion. The anatomopathological mechanisms of different types of strokes occurs in conditions of severe hypotension or in paroxysmal rhythm disorders. Confirming the diagnosis of a stroke is usually easy if the anamnesis is known [7-10 ]. Any sudden neurological deficit that involve an arterial territory must be considered a stroke. The differentiation between ischemic stroke (IS) and transient ischemic stroke (TIS) has no practical interest since the patient should be seen and treated in a similar manner in the first 24 hours and there is nothing to affect the clinical deficit. Usually, TIS announces a future constituted stroke.

MRI investigation is one of the most sensitive paraclinical diagnostic methods in the case of stroke. It is more sensitive than tomography, highlighting recent ischemic strokes, with signal abnormalities occurring a few hours after the ischemic process. It is also more sensitive in highlighting old post-haemorrhagic sequelae.

For high accuracy, contrast-injected MRI technique is used. There are numerous studies in specialised literature that assume that this radiological investigation technique is overstated by other emerging techniques and, in some situations, it may even be dangerous [ 11-13].

The purpose of our study is to show the usefulness of the radiological technique of MRI with contrast substance and to propose a protocol for the investigation of clinically diagnosed patients with stroke by this method.

*email: cstatescu@gmail.com; radusascau@gmail.com; tudor.cuciureanu@umfiasi.ro 


\section{Experimental part}

\section{Material and methods}

Our study was conducted on a group of 165 selected patients diagnosed with different forms of IS, aged between 25 and 50 years, admitted to the I-st Neurology Clinic of the "Prof. Dr. Nicolae Oblu" Clinical Hospital in the period 2014-2018.

The 165 cases were analyzed taking into account all aspects of the epidemiological and etiopathogenic data suggested by the clinical examination and revealed by the laboratory examinations.

The examination was performed following the clinic protocol, with particular attention to clinical, ophthalmic, cardiological, ECG, and ECHO Doppler vascular examinations.

All the selected patients were examined by MRI contrast technique after initial native scan. This was performed after entire routine examination protocol.

We must emphasize that patients or their owners have previously signed the informed consent forms on the methods of investigation and treatment.

The contrast agent routinely used in MRI examinations is based on iodine in various combinations and concentrations, with lately developing isosomolar and hypoallergenic compounds in order to reduce the frequency of possible side effects.

The radiologist will decide upon the need to use the contrastagent in the course of the investigation, depending on the pathology of the patient and of course the changes encountered during the initial native scan and taking into account the benefit/risk ratio of each case.

Routine contrast agents are used in MRI examinations to increase the natural contrast of blood vessels and certain portions of the encephalus, resulting in a diagnosis of certainty. In the case of highlighted injuries, their particular vascular criteria give additional information for diagnosis.

For this we used the following exam protocol:

- weight ratio in sagittal section (number of slots 30, slice thickness $4 \mathrm{~mm}$, matrix 218×256, TA 3:20)

- weighted t2 sagittal iso_1.0 (3D sequence, sagittal acquisition and axial and cöronal reconstruction, $1 \mathrm{~mm}$ acquisition and reconstruction slice, matrix $202 \times 256$, TA 5:17)

- ep2d diff 3scan trace p2 (diffusion, slice number 30, slice thickness $4 \mathrm{~mm}^{-}$, matrix 192x192, TA 2:18)

- t2_swi3d tra (slice number 30 , slice thickness $2 \mathrm{~mm}$, matrix 186x256, TA 3:38)

- spc ir_cor p2 iso (oblique, perpendicular to the hippocampus) (3D sequence, coronal acquisition and axial reconstruction, $1 \mathrm{~mm}$ acquisition and reconstruction slice, 202x256 array, TA 4:26)

- t2 tse cor (oblique, perpendicular to the hippocampūs) (slice number 50, slice thickness $2 \mathrm{~mm}$, TA 4:26, matrix $307 \times 256)$

- t1 mprage tra (3D sequence, axial acquisition and sagiatāl and coronal reconstruction, $1 \mathrm{~mm}$ reconstruction acquisition slice, 246x256 array, TA 5:34) Contrast agent injected

- t1 mprage tra (3D sequence, axial acquisition and sagittaT and coronal reconstruction, $1 \mathrm{~mm}$ acquisition and reconstruction slice, 246x256 matrix, TA 5:34)

- t1_se tra 320 MTC (slice number 30, slice thickness 4mm, matrix 256x320, TA 3:25)

Device Type: Siemens Essenza Tim-Dot, 1.5T

Abbreviations list: $\mathrm{TA}=$ acquisition time; Total $\mathrm{TA}=$ $45 \mathrm{~min} ; \mathrm{FOV}=$ field of view $=230-250 \mathrm{~mm}$.

\section{Results and discussions}

The cases investigated by the mentioned protocol were diagnosed as follows:

-82 patients with atherosclerotic stroke (49.70\%);

-78 with embolic stroke (47.27\%);

-5 with haemorrhagic stroke (3.03\%).

Five of them died shortly after paraclinical investigation due to the severity of stroke and associated comorbidities. $58 \%$ of the patients were male and $42 \%$ females.

The obtained images emphasizes the utility of contrast agents in MRI examination and the particularly high degree of acuity of this technique.

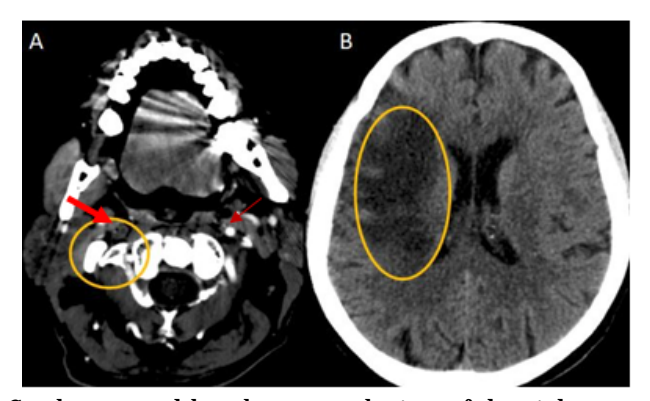

Fig.1 Stroke caused by plaque occlusion of the right common carotid artery; $A=M R I$ with contrast substance; $B=$ native MRI that highlights the affected brain territory

In patients with atherosclerotic disease, $92.13 \%$ of the strokes occurred in the territory of the internal carotid artery (fig. 1).

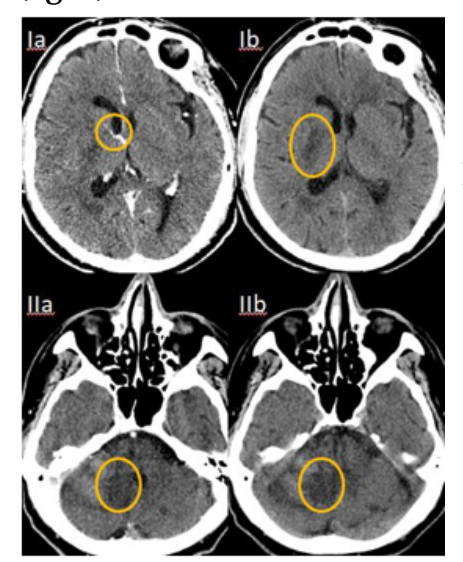

Fig.2 Thrombotic stroke; I = on the middle right brain artery; II $=$ on the right cerebellar artery; $a=$ MRI with contrast substance; $b=$ native IRM

In the case of patients with embolic strokes, the territory of the internal carotid artery was also predominantly affected but with lesser extent - $53.85 \%$ (fig. 2).

Most of the haemorrhagic strokes ( $80 \%$ ) occurred in the territory of the internal carotid artery (fig. 3).

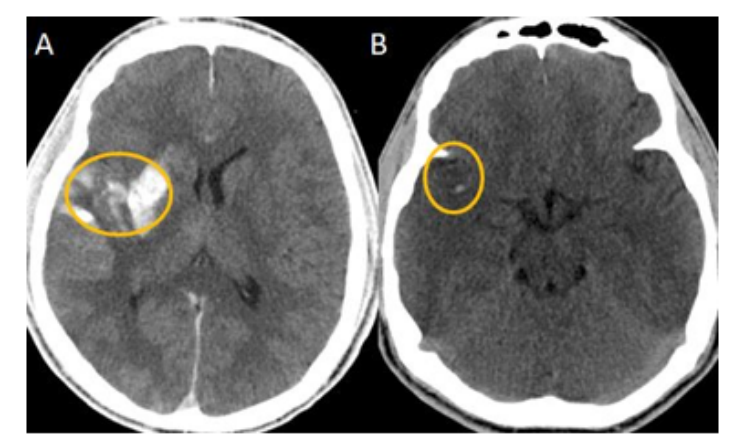

Fig.3 MRI in patients with haemorrhagic vascular accident; $A=$ with contrast substance; $B=$ native 
In the case of vascular accidents due to atherosclerosis and embolic causes, the MRI contrast technique shows with high acuity the affected blood vessel and its segment.

In the case of haemorrhagic vascular accidents, besides the objection of the affected blood vessel, the MRI with the contrast substance shows the degree of extravasation of the blood flow.

This is performed in T1-weighted images, left field without and right field with contrast medium administration. We have used Omniscan which is a gadodiamide and Magnevist which is a gadopentetate substance.

T2-based arterial spin labeling (ASL) method with 3D readout could be used to measure the water transfer processes between arterial blood and brain tissue based on a 3D-GRASE (gradient and spin echo) pulsed ASL sequence with multiecho readout. Also, these agents are used for highlighting the blood vessels in MRI angiography and/or brain tumor associated with the degradation of the blood-brain barrier. In case of large blood vessels gadolinium dose could be lowered to $0.1 \mathrm{mmol} / \mathrm{kg}$ body mass and higher concentrations are used for thinner vasculature. This great utility of the paramagnetic agents is given by the chelates they contain which do not pass the intact blood-brain barrier because they are hydrophilic. Thus, these are useful in enhancing lesions and tumors where blood-brain barrier is compromised and the Gd leaks out. After a while the contrast agent will distribute into the interstitial space and will be eliminated by the kidneys.

Apart from the already known advantages of the IRM radiological investigation technique, particularly in the case of brain exploration, it has some great advantages [1416]. These include the high acuity and sensitivity of this technique, the possibility of functional explorations and $3 \mathrm{D}$ reconstruction.

Native exploration is important in highlighting the affected brain territory $[17,18]$.

Applying these notions to patients diagnosed with stroke, MRI is of particular interest.

In MRI, the very recent hematoma is iso-intensive in $\mathrm{T} 1$ and hypointense in T2. Gadolinium (Gd/paramagnetic) are the most common agents used to detect the efect upon the blood-brain barrier [19-21] of a stroke shown in MRI. These signals change differently to become hyperintense on $\mathrm{T} 1$ and $\mathrm{T} 2$ from day 5 . From day 15 , a hyposignal ring appears at $\mathrm{T} 1$ and $\mathrm{T} 2$, corresponding to hemosiderin deposits.

Exploration includes blood and tissue compartment, $\mathrm{T} 1$ and $T 2$ relaxation, and a blood-to-tissue transfer sequency $[22,23]$. T1 sequences are extremely useful in detecting transient ischemic strokes and their differentiation from epilepsy attacks or other causes of loss of consciousness $[24,25]$.

Even if gadolinium-based contrast agents appear to be safe in pregnancy, none of the female patients in our group was confirmed so [26-29].

In case of contrast-extravasation following haemorrhagic stroke, the images obtained by MRI technique are also iso-intensive in $\mathrm{T} 1$ and hypointense in T2.

In the case of thrombotic cerebral accidents, $\mathrm{T} 1$ weighs an iso-intensive signal on both sides of the lesion and hypointense in $\mathrm{T} 2$.

Certain studies in the literature show that iodinated contrast agents used in CT and MRI techniques could disrupt the effect of thrombolytic medication. This would mean that the method is contraindicated in patients diagnosed with embolic stroke. This theory has not been proven, and is thus denied.
MRI with contrast substance is more useful for patients diagnosed with embolic stroke as long as blood-brain barrier permeability changes can be tracked, using dynamic contrast-enhanced magnetic resonance imaging.

Iron oxide (I0) nanoparticles such as Ferumoxytol are being increasingly used to image cellular contribution to neuroinflammation using MRI. They provide additional information on neuroinflammatory phenomena, as compared to conventional Gadolinium-enhanced MRI. This is posible because these particles are allowing to assess cell trafficking from the blood to neuroinflammation sites by phagocytic activity. They have a widespread availability and relatively low costs together with great accuracy [3032].

In this way, vascular intracerebral phenomena occurring after reperfusion of affected area can be monitored by native MRI also [33].

Knowing the functional anatomy of the blood-brain barrier is of utmost importance for the understanding of ischemia-reperfusion injuries that are directly related to haemorrhagic transformation. rtPA (the recombinant human plasminogen activator) increases the risk of symptomatic post-reperfusion intracranial haemorrhage. Modern radiological techniques allow understanding of the pathological disorders of blood-brain barrier, and MRI can be a rigorous method for assessing the risk of bleeding. In this regard, a micellar polymeric MRI contrastagent is used [34- 39].

\section{Conclusions}

MRI with contrast substance is a basic technique in diagnosing and evaluating the prognosis of patients diagnosed with stroke. The use of special contrast agents opens the way for their MRI functional exploration and monitoring.

\section{References}

1.AMARENCO, P., BOGOUSSLAVSKY, J., CAPLAN, L.R., DONNAN, G.A., HENNERICI, M.G., Cerebrovasc Dis., 27, no. 5, 2009, p. 493. 2.BAMFORD, J ., SANDERCOCK, P.A., DENNIS, M.S., BURN, J ., WARLOW, C.P:, Lancet, 337, 1991, p. 1521.

3.ADAMS, H.P., BENDIXEN, B.H., KAPPELLE, L.J., BILLER, J., LOVE, B.B., GORDON, D.L., MARSH, E.E., Stroke, 24, 1993, p. 35.

4.AY, H., FURIE, K.L., SINGHAL, A., SMITH, W.S., SORENSEN, A.G., KOROSHETZ, W.J ., Ann Neurol, 58, 2005, p. 688.

5.GOLDSTEIN, L.B., JONES, M.R., MATCHAR, D.B., LLOYD, J.E., HOFF, J., CHILUKURI, V., ARMSTRONG, S.B., HORNER, R.D., Stroke, 32, 2001, p. 1091.

6.MOHR, J.P., CAPLAN, L.R., MELSKI, J.W., GOLDSTEIN, R.J., DUNCAN, G.W., KISTLER, J.P., PESSIN, M.S., BLEICH, H.L., Neurology, 28, 1978, p. 754.

7.MINDRUTA, I.R., BAJENARU, O.A., PANEA, C.A., et al. Experience with lacosamide in treating focal epilepsy patients in Romania: efficacy, safety and time to reach response [abstract no. p332]. Epilepsia. 2014;55(Suppl 2):110.

8.HINGANU, D., HINGANU, M.V., MIHALCEANU, E., CALIN, A.M., PANGAL, A., COSTACHESCU, G., ROMILA, A., Rev.Chim.(Bucharest), 69, no. 2, 2018, p. 714.

9.SALARU, D.L., MACOVEI, L., STATESCU, C., ARSENESCUGEORGESCU, C., Assessment of microalbuminuria in hypertensive patients with established coronary artery disease. REVISTA ROMANA DE MEDICINA DE LABORATOR, 21, no.4, 2013, p. 407. DOI: 10.2478/ rrlm-2013-0041

10.VASILCU, T.F., STATESCU, C., SASCAU, R., ROCA, M., COSTEA, C.F., ZOTA, M., BARARU, I., CONSTANTIN, M.L., MITU, F., Rev.Chim.(Bucharest), 69, no.8, 2018, p. 2283

11.KILINC, Y., SASMAZ, I., BOZKURT, A., ANTMEN, B., ACARTÜRK, E., Curr Ther Res Clin Exp., 64, no.7, 2003, p. 461. 
12.ING, J.J , SMITH, D.C., BULL, B.S., Radiology, 172, 1989, p.:345. 13.RUSU, A.R.G., TARTAU, L.M., STATESCU, C., BOANCA, M., POROCH, V., LUPUSORU, R.V., DIMA, N., BADESCU, C., REZUS, E., REZUS, C., LUPUSORU, C.E., Rev.Chim.(Bucharest), 69, no.6, 2018, p. 1493. 14.HINGANU, D., SCUTARIU, M.M., HÎNGANU, M.V., The existence of labial SMAS - Anatomical, imaging and histological study. Annals of Anatomy-Anatomischer Anzeiger, 218, 2018, p. 271. https://doi.org/ 10.1016/j.aanat.2018.04.009

15.HINGANU, M.V., HINGANU, D., COZMA, S.R., ASIMIONOAIEISIMIONESCU, C., SCUTARIU, I.A., IONESIE, D.S., HABA, D., Annals of Anatomy, 220, 2018, p.1; https://doi.org/10.1016/j.aanat.2018.06.008 16.CUCIUREANU, D.I., CONSTANTINESCU, I.M., DANCIU, F., CUCIUREANU, T., Brain tuberculomas revealed by epileptic generalized seizures after tuberculostatic treatment: a case report. [abstract no. p0516]. Epilepsia; 2015; 56(suppl. 1): 128.

17.DICKIE, B., VANDESQUILLE, M., ULLOA, J., BOUTIN, H., PARKES, L.M., LAURA, M., GJ M. Neuroimage, 184, 2019, p. 349..

18.ARMITAGE, P.A., FARRALL, A.J., CARPENTER, T.K. etal.. Magn Reson Imaging Volume, 2011, 29, no. 3, p. 305.

19.ABBOTT, N.J ., PATABENDIGE, A.A.K., DOLMAN, D.E.M., et al., Neurobiol Dis, 2010, 37, no.1, p. 13.

20.BOANGHER S, MESPOUILLE P, GOFFETTE S, VAN PESCH V, CUCIUREANU D. Herpes simplex encephalitis relapse associated with positive N-methyl-d-aspartate receptor antibodies. Acta Neurologica Belgica; 2018; 118(4): 533-535. DOI: 10.1007/s13760-0180897-9

21.CONSTANTINESCU V, MATEI D, CUCIUREANU D, CORCIOVA C, IGNAT B, POPESCU CD. Cortical modulation of cardiac autonomic activity in ischemic stroke patients. Acta Neurologica Belgica; 2016; 116(4): 473-480DOI: 10.1007/s13760-016-0640-3

22.GREGORI, J., SCHUFF, N., KERN, R., GUNTHER, M., J Magn Reson Imaging, 37, no.2, p.332

23.LIU, P., UH, J., LU, H., http://apps.webofknowledge. com.dbproxy. umfiasi. ro/CitedFullRecord.do? product $=$ WOS\&co IName= WOS\&SID=Ellg6 W blxgxq QKVIA8E\& search_mode = CitedFull Record\&isickref =WOS: 000285963500013 Magn Reson Med Sci Volume, 65, no.1, 2011, p. 120.

24.CUCIUREANU DI, CUCIUREANU T, CUCIUREANU A. Neurotic disorder and unexpected EEG records in apparent healthy people. [abstract no. p935]. J ournal of the Neurological Sciences. 2017; 381 (suppl S): 339.
25.CUCIUREANU DI, NITA A, CUCIUREANU A, CUCIUREANU T , CONSTANTINESCU IM. Experience with first episode of consciousness loss assessment in a regional center of Romania. [abstract no. p638]. Epilepsia. 2016; 57 (suppl. 2): 194.

26.LENTSCHIG, M.G., REIMER, P., RAUSCH-LENTSCHIG, U.L., ALLKEMPER, T., OELERICH, M., LAUB, G., Radiology, 208, no.2, 1998, p. 353. doi:10.1148/radiology.208.2.9680558. PMID 9680558.

27.GARCIA-BOURNISSEN, F., SHRIM, A., KOREN, G., Can Fam Physician. 52, 2006, p. 309. PMC 1479713. PMID 16572573.

28.*** EUROPEAN MEDICINES AGENCY, recommendations on Gadolinium-containing contrast agents. ema.europa.eu. Retrieved 2018-07-12.

29.EUROPEAN MEDICINES AGENCY, Information on GadoliniumContaining Contrast Agents. Fda.gov. Retrieved 2018-07-12.

30.UGGA， L., ROMEO, V., TEDESCHI, E., BRUNETTI, A., QUARANTELLI, M., J Neurosci Methods, 310, p. 12; Special Issue: SI.

31.AGHIGHI, M., GOLOVKO, D., ANSARI, C. et al., PLOS ONE, 10, no.11, Article Number: e0142665; 162015.

32.BULTE, JEFF W.M., KRAITCHMAN, DARA L., NMR in Biomedicine. 17, no.7, 2004, p.484.

33.LIN ZX, LI Y, SU P, MAO D, WEI ZL, PILLAI J), MOGHEKARA, VAN OSCH M, GE YL, LU HZ, Magn Reson Med Sci, 80, no. 4, p.1507.

34.KOUICHI, S., ZUOJ UN, W., DAISUKE, K., ICHIO, A., MASAYUKI, Y. A polymeric micelle magnetic resonance imaging (MRI) contrast agent reveals blood-brain barrier (BBB) permeability for macromolecules in cerebral ischemia-reperfusion injury. 2017. J ournal of Controlled Release 253

35.KRUEGER, M., BECHMANN, I., IMMIG, K., REICHENBACH, A., HARTIG, W., MICHALSKI, D., J Cereb Blood Flow Metab., 35, no.2, 2015, p. 292.

36.W HITELEY, W.N., THOMPSON, D., MURRAY, G., COHEN, G., LINDLEY, R.I., WARDLAW, J. et al., Stroke 45, 2014, p. 1000.

37.HINGANU, M.V., SALAHORU, P., HINGANU, D., Rev Med Chir Soc Med Nat lasi, 122, no.3, 2018, p. 522.

38.CONSTANTINESCU, V., MATEI, D., COSTACHE, V., CUCIUREANU, D., ARSENESCU-GEORGESCU C., NEUROLOGIA I NEUROCHIRURGIA POLSKA, 52, no.2, 2018, p.194.

39.ROMANEC, C., PACURAR, M., DECUSARA, M., SCUTARIU, M.M, HINGANU, D., HINGANU, M.V., CIUPILAN, C., Rev.Chim.(Bucharest), 69, no.4, 2018, p. 1002.

$\overline{\text { Manuscript received:8.08.2018 }}$ 